\title{
POLÍTICAS E GESTÃO DA EDUCAÇÃO SUPERIOR A DISTÂNCIA: NOVOS MARCOS REGULATÓRIOS?
}

\author{
Luiz Fernandes Dourado*
}

\begin{abstract}
RESUMO: ao problematizar as políticas e gestão atuais para a educação básica e superior, o artigo enfoca os novos marcos regulatórios do processo expansionista e analisa as políticas direcionadas à formação de professores, com especial realce para a educação a distância no setor público. Nessa direção, apresenta e analisa alguns indicadores educacionais e busca apreender, no campo das políticas propostas pelo MEC, o papel da "Nova CAPES" como espaço de regulação das políticas de formação de professores, enfatizando a expansão pública, na modalidade EaD, por meio dos desafios da consolidação da Universidade Aberta do Brasil (UAB).

Palavras-chave: Educação superior a distância. Expansão pública. Regulação.
\end{abstract}

\section{Politics AND MANAGEMENT OF THE SUPERIOR EDUCATION IN THE DISTANCE: NEW REGULATORY LANDMARKS?}

ABSTRACT: To evaluate the current politics and management for the basic and superior education, the article focuses new regulatory landmarks of the expansion process and analyzes the politics directed to the formation of professors, with special distinction for the education in the distance in the public sector. In this direction, it presents and it analyzes some educational pointers and it searchs to apprehend, in the field of the politics proposals for the MEC, the paper of the "New CAPES" as space of regulation of the politics of formation of professors, emphasizing the public expansion, in the

Doutor em Educação e professor titular do Programa de Pós-Graduação em Educação Brasileira, da Faculdade de Educação da Universidade Federal de Goiás (UFG). E-mail: douradol@terra.com.br 
Políticas e gestão da educação superior a distância: novos marcos regulatórios?

EaD modality, by means of the challenges of the consolidation of the Open University of Brazil (UAB).

Key words: Superior education in the distance. Public expansion. Regulation.

\section{Introdução}

$\mathcal{A}$

globalização (ou mundialização) apresenta-se marcada por paradoxos e contradições, que retratam o caráter difuso e articulado desta nova fase de acumulação capitalista. Assim, Segundo Ianni (2000, p. 144),

$\mathrm{Na}$ época da globalização modificam-se mais ou menos radicalmente as condiçôes sob as quais se desenvolvem a teoria e a prática da Política. Em primeiro lugar, a globalização do capitalismo, como modo de produção e processo civilizatório, propicia o desenvolvimento de relações, processos e estruturas de dominação política e apropriação econômica de alcance mundial. Alteram-se as formas de sociabilidade e os jogos das forças sociais, no âmbito de uma vasta, complexa e contraditória sociedade civil mundial em formação. Isto significa a emergência e dinâmica de grupos sociais, classes sociais, estruturas de poder, acomodações, tensões e lutas em escala mundial. Em segundo lugar, no bojo desse mesmo processo de globalização político-econômica e sociocultural, desenvolvem-se tecnologias eletrônicas, informáticas e cibernéticas que agilizam, intensificam e generalizam as articulaçōes, as integrações, as tensôes, os antagonismos, as fragmentaçôes e as mudanças sócio-culturais e político-econômicas pelos quatro cantos do mundo. Em terceiro lugar, e simultaneamente a todos os desenvolvimentos, nexos, contradiçôes e transformações em curso, desenvolve-se uma nova configuração histórico-social de vida, trabalho e cultura, desenhando uma totalidade geoistórica de alcance global, compreendendo indivíduos e coletividades, povos, nações e nacionalidades, culturas e civilizações. Esse é o novo e imenso palco da história, no qual se alteram mais ou menos radicalmente os quadros sociais e mentais de referências de uns e outros, em todo o mundo.

Essa dinâmica social, marcada por apropriação econômica em escala mundial, potencializa o desenvolvimento de relações, processos e estruturas de dominação e, ao alterar as formas de sociabilidade, propicia, paradoxalmente, a emergência de "grupos sociais, classes sociais, estruturas de poder, acomodações, tensões e lutas em escala mundial”. 
É neste cenário de mudanças sociais, intensificadas pela progressiva diferenciação dos ambientes geopolíticos e por expressivo e desigual avanço tecnológico, que se efetivam alterações no mundo do trabalho e da produção, as quais, por seu turno, redimensionam as esferas da atividade humana. Estabelece-se, portanto, um espaço contraditório, em que se generalizam e desenvolvem tecnologias favoráveis à integração e, paradoxalmente, a novas formas de inclusão dependente. Tal processo não é resultante, em si mesmo, do avanço tecnológico, mas sim das novas formas de acomodação histórica do modo de produção capitalista que alteram as formas de sociabilidade e, conseqüentemente, a relação entre as forças sociais, que, sob a hegemonia do ethos privado, sofrem a influência das tecnologias eletrônicas, informáticas e cibernéticas.

Nesse cenário, a situação de países como o Brasil - com alto avanço tecnológico e, ao mesmo tempo, com parcela significativa da população em situação de extrema pobreza -, historicamente estruturado por desigualdades sociais intensas, agrega inúmeros outros desafios. Aqui, o padrão de relacionamento entre Estado e sociedade é, ainda, marcado por relaçóes patrimonialistas sob o domínio dos interesses da esfera privada em detrimento da esfera pública. Assim, um dos nossos grandes desafios é ampliar os direitos sociais e coletivos, tais como: habitação, saúde e educação.

Nesse contexto, a reflexão sobre as políticas educacionais nos remete à compreensão dos complexos processos de sua regulação e regulamentação, bem como da relação entre a proposiçãao e a materialização das açōes e programas direcionados aos sistemas educativos. A análise de indicadores educacionais e seus desdobramentos torna-se, assim, referência fundamental na identificação dos limites e desafios para a concretização de políticas educacionais.

\section{Educação básica e superior no Brasil: caracterização e indicadores}

O cenário educacional traduz a realidade desigual e combinada do Estado brasileiro, com enorme descompasso entre os diferentes níveis e modalidades de educação no que diz respeito ao acesso.

$\mathrm{Na}$ tabela 1, identificamos que os estados/Distrito Federal e municípios são responsáveis por $86,55 \%$ das 55.942 .047 matrículas na educação básica, respondendo, respectivamente, por $41,43 \%$ e $45,12 \%$ 
Políticas e gestão da educação superior a distância: novos marcos regulatórios?

das matrículas nesse nível de ensino, enquanto que o setor privado responde por $13,13 \%$ e a União por apenas $0,32 \%$. Tais indicadores revelam que há predomínio de matrículas no setor público.

\section{Tabela 1}

Número de matrículas de educação básica, por dependência administrativa, segundo a região geográfica e a unidade da Federação: 29/03/2006

\begin{tabular}{|c|c|c|c|c|c|}
\hline \multirow{2}{*}{$\begin{array}{c}\text { Unidade da } \\
\text { Federação }\end{array}$} & \multirow{5}{*}{ Total } & \multicolumn{4}{|c|}{ Dependência Administrativa } \\
\cline { 3 - 6 } & & Federal & Estadual & Municipal & Privado \\
\cline { 3 - 6 } & & & & & \\
\hline & & 177.121 & 23.175 .567 & 25.243 .156 & 7.346 .203 \\
\hline
\end{tabular}

Fonte: MEC/ INEP/DAES (2006).

Por outro lado, se considerarmos que o ensino fundamental é responsável, segundo o censo de 2006, por 33.282.663 do total de matrículas da educação básica (55.942.047), é possivel identificar que, historicamente, tal etapa ocupou papel central no campo das políticas educacionais, envolvendo, sobretudo, a ação de estados e municípios e o apoio técnico e financeiro do governo federal. ${ }^{1} \mathrm{Na}$ década de 1990 , a opção preferencial do governo federal foi estimular a universalização do ensino fundamental, por meio do Fundo de Manutenção e Desenvolvimento do Ensino Fundamental e de Valorização do Magistério (FUNDEF). ${ }^{2} \mathrm{O}$ resultado de tais políticas propiciaram o incremento do número de matrículas nesta etapa, em detrimento das demais. Este contexto revela o enorme esforço a ser ainda despendido para ampliar o acesso à educação infantil e ao ensino médio, que respondem, respectivamente, segundo o censo de 2006, por apenas $12,54 \%$ e $15,92 \%$ das 55.942.047 matrículas na educação básica. Por outro lado, é fundamental destacar o crescimento das matrículas na modalidade de educação de jovens e adultos (10,04\%), sem perder de vista a importância da expansão verificada no ensino fundamental. ${ }^{3}$ Outro dado a ser objeto de reflexão refere a articulação da educação profissional a esse processo. ${ }^{4}$

Outro aspecto importante a salientar, nesse contexto, refere-se à aprovação do Fundo de Manutenção e Desenvolvimento da Educação Básica e de Valorização do Magistério (FUNDEB), em 2007, que 
representa um avanço nas políticas de financiamento frente ao FUNDEF, malgrado os problemas a serem superados em relação ao custo alunoqualidade e à efetiva colaboração entre as redes de ensino. ${ }^{5}$

A análise de tais indicadores sinaliza, portanto, a necessidade de expansão desse nível de ensino e, ainda, do aprimoramento dos processos formativos a todos aqueles que buscam acesso às diferentes etapas e modalidades que compõem a educação básica. Se considerarmos que estados, Distrito Federal e municípios são os principais entes responsáveis pelo acesso e expansão desse nível de ensino, contando com o apoio técnico e financeiro da União, faz-se necessário rediscutir um conjunto de questôes, incluindo, entre outros, o regime de colaboração, o financiamento e o controle social da educação, parâmetros e diretrizes para a formação e profissionalizaçao de trabalhadores em educação e a efetivação de um sistema nacional de educação. ${ }^{6}$ Esse conjunto de questôes nos conduz a pensar a educação básica articulada à educação superior, bem como a aliança entre as políticas, programas e ações propostos e/ou em efetivação nos dois níveis de ensino.

No tocante à educação superior, os dados educacionais indicam complexos desafios a serem superados. Em que pese a expansão vivenciada pelo sistema, sobretudo na última década, e a despeito de revelarem incremento substantivo das matrículas, os indicadores ainda revelam os enormes desafios interpostos à garantia do acesso a esse nível de ensino, principalmente para a população entre 18 e 24 anos, em padróes aceitáveis internacionalmente e em consonância com as metas do Plano Nacional de Educação (PNE). ${ }^{7}$

Os indicadores educacionais relativos a matrículas (tabela 2) em cursos de graduação presenciais, em 2006, registram a manutenção da lógica privatista da educação superior, intensificada, sobretudo, a partir da segunda metade da década de 1990. Assim, em 2006, o setor privado (instituiçôes de ensino superior [IES] particulares, comunitárias, confessionais e filantrópicas) passou a responder por $74,14 \%$ das 4.676 .646 matrículas em cursos presenciais. Se considerarmos os dados relativos apenas às IES particulares, elas respondem por 1.924.166 matrículas, enquanto as IES públicas (federais, estaduais e municipais) respondem por apenas 1.209.304 matrículas em cursos presenciais, em 2006.

Como tendência desse processo expansionista, merece ser ressaltado, ainda, o incremento de matrículas via interiorização das IES. Nessa 
Políticas e gestão da educação superior a distância: novos marcos regulatórios?

direção, os dados retratam que as instituições localizadas no interior respondem por $55,16 \%$ do total de matrículas, enquanto as IES localizadas nas capitais respondem pelas matrículas restantes.

\section{Tabela 2}

Número de matrículas em cursos de graduação presenciais - Brasil (2006)

\begin{tabular}{|c|r|r|r|}
\hline \multirow{2}{*}{$\begin{array}{c}\text { Número de matrículas } \\
\text { Brasil/Categoria administrativa }\end{array}$} & \multicolumn{3}{|c|}{ Total Geral } \\
\cline { 2 - 4 } & \multicolumn{1}{|c|}{ Total } & \multicolumn{1}{|c|}{ Capital } & \multicolumn{1}{c|}{ Interior } \\
\hline Brasil & 4.676 .646 & 2.096 .910 & 2.579 .736 \\
Pública & 1.209 .304 & 517.831 & 691.473 \\
Federal & 589.821 & 395.201 & 194.620 \\
Estadual & 481.756 & 120.920 & 360.836 \\
Municipal & 137.727 & 1.710 & 136.017 \\
Privada & 3.467 .342 & 1.579 .079 & 1.888 .263 \\
Particular & 1.924 .166 & 943.459 & 980.707 \\
Comun/Confes/Filant & 1.543 .176 & 635.620 & 907.556 \\
\hline
\end{tabular}

Fonte: INEP (2006).

A análise da evolução do número de vagas oferecidas em cursos presenciais de graduação, no período de 1980 a 2006, confirma a intensificação do processo de privatização da educação superior, particularmente após 1995. Tal dinâmica é resultante da lógica política implementada, que, ao aliar o processo expansionista desse nível de ensino ao setor privado, propiciou centralidade à expansão de IES particulares.

Assim, por meio das mudanças introduzidas nas políticas e gestão desse nível de ensino, com especial destaque para os processos de diversificação e diferenciaçãoo institucionais naturalizados na década de 1990, o ensino superior privado solidificou sua atuação, na medida em que alterou substantivamente a perfomance, ampliando sua presença nos seguintes termos, segundo dados da tabela 3: em 1980, o ensino superior privado respondia por $68,64 \%$ das 404.814 vagas; em 1990 , passou a responder por $69,16 \%$ das 502.784 ; em 1995 , por $70,81 \%$ 
das 610.355 vagas; em 2000 , por $79,8 \%$ das 1216.287 vagas; em 2002 , por $83,34 \%$ das 1.773 .087 vagas; e, finalmente, em 2006, passou a responder por $87,41 \%$ das 2.629 .598 vagas para a educação superior. Trata-se, como afirmamos anteriormente, de lógica de expansão predominantemente privada.

A análise dos dados nos permite, ainda, identificar no setor público uma discreta e constante evolução dos indicadores relativos à educação superior federal, intensificada a partir de 2003. No caso dos estados, o processo expansionista, ao longo de todo o período, foi fortemente marcado pela criação de novas IES e cursos e por processos de consolidação institucional. No caso das IES municipais, os indicadores evidenciam uma pequena evolução entre 1980 e 2006 e, paradoxalmente, apresentam oscilação dos indicadores ao longo de todo o período. Tal situação pode retratar o caráter ambíguo destas IES, que, em muitos casos, se estruturam como fundações de natureza pública e caráter privado. ${ }^{9}$

\section{Tabela 3}

Evolução do número de vagas oferecidas em vestibular e outros processos seletivos no ensino superior de graduação presencial, por categoria administrativa - Brasil $(1980 / 2006)$

\begin{tabular}{|c|c|c|c|c|c|c|c|c|c|c|}
\hline \multirow{3}{*}{ Ano } & \multirow{2}{*}{\multicolumn{2}{|c|}{ Total }} & \multicolumn{8}{|c|}{ Categoria Administrativa } \\
\hline & & & \multicolumn{2}{|c|}{ Federal } & \multicolumn{2}{|c|}{ Estadual } & \multicolumn{2}{|c|}{ Municipal } & \multicolumn{2}{|c|}{ Privada } \\
\hline & Vagas & $\begin{array}{c}\text { Ano-Base } \\
1980\end{array}$ & Vagas & $\begin{array}{c}\text { Ano-Base } \\
1980\end{array}$ & Vagas & $\begin{array}{c}\text { Ano-Base } \\
1980\end{array}$ & Vagas & \begin{tabular}{|c|} 
Ano-Base \\
1980
\end{tabular} & Vagas & \begin{tabular}{|c} 
Ano-Base \\
1980
\end{tabular} \\
\hline 1980 & 404814 & 100 & 65406 & 100 & 33618 & 100 & 27916 & 100 & 277874 & 100 \\
\hline 1985 & 430482 & 106 & 67307 & 103 & 41055 & 122 & 32912 & 118 & 289208 & 104 \\
\hline 1990 & 502784 & 124 & 70881 & 108 & 55232 & 164 & 28896 & 104 & 347775 & 125 \\
\hline 1995 & 610355 & 151 & 84814 & 130 & 61352 & 182 & 31979 & 115 & 432210 & 156 \\
\hline 2000 & 1216287 & 300 & 120486 & 184 & 96179 & 286 & 28967 & 104 & 970655 & 349 \\
\hline 2002 & 1773087 & 438 & 124196 & 190 & 132270 & 393 & 38888 & 139 & 1477733 & 532 \\
\hline 2006 & 2629598 & 650 & 144445 & 221 & 125871 & 374 & 60789 & 218 & 2298493 & 827 \\
\hline
\end{tabular}

Fonte: MEC/INEP.

O processo de diversificação e diferenciação institucional, naturalizado após 1995 no país, sinaliza, ainda, importantes movimentos na educação superior brasileira, ao mesmo tempo em que revela a organicidade das políticas propostas e implementadas. Nesse contexto, segundo a tabela 4 , houve, no período, o incremento de matrículas em 
Políticas e gestão da educação superior a distância: novos marcos regulatórios?

universidades do setor privado, passando de 660 mil, em 1997, para 1.457 mil, em 2006 (por meio de expansão da ação institucional, criação de novas universidades, cursos e vagas); a explosiva criação de centros universitários, instituiçóes tipicamente de ensino, que saltaram de 30 mil matrículas, em 1997, para 711 mil, em 2006; e um pequeno incremento de matrículas em faculdades integradas, que passaram de 161 mil para 197 mil matrículas. No tocante às faculdades, escolas e institutos (que compoem o caso de IES isoladas, predominamente de pequeno porte) da esfera privada, estes vivenciaram um processo expansionista sem precedentes, ao passarem de 335 mil matrículas, em 1997, para 1.051.000 matrículas, em 2006. Merece ser ressaltado, como movimento recente no campo da educação superior privada, o incremento de matrículas por meio da criação de centros de educação tecnológica, que passaram de 6 mil matrículas, em 2002, para 50 mil, em 2006.

O setor público, no período, manteve como tendência a consolidação de suas ações de maneira predominante em universidades, ampliando, nesta dependência administrativa, o número de matrículas de 666 mil, em 1997, para 1.053.000, em 2006. As demais dependências responderam por apenas 93 mil matrículas, em 1997, e 156 mil, em 2006. Também no setor público, ocorreu o aumento de matrículas por meio da criação de centros de educação tecnológica, que passaram de 37 mil matrículas, em 2002, para 48 mil, em 2006.

\section{Tabela 4}

Evolução da matrícula no ensino superior de graduação presencial, por rede, segundo a organização - Brasil (1994/2006)

\begin{tabular}{|l|r|r|r|r|r|r|r|r|r|r|r|r|r|r|}
\hline \multicolumn{1}{|c|}{ Organizaçāo Acadêmica } & \multicolumn{3}{|c|}{ Total } & \multicolumn{3}{c|}{ Pública } \\
\cline { 2 - 13 } & 1994 & 1997 & 2002 & 2006 & 1994 & 1997 & 2002 & 2006 & 1994 & 1997 & 2002 & 2006 \\
\hline Total & 1661 & 1946 & 3480 & 4677 & 690 & 759 & 1052 & 1209 & 971 & 1186 & 2428 & 3467 \\
Universidades & 1035 & 1326 & 2151 & 2510 & 572 & 666 & 916 & 1053 & 463 & 660 & 1235 & 1457 \\
Centros Universitários & $\ldots$ & 30 & 430 & 728 & $\ldots$ & - & 15 & 16 & $\ldots$ & 30 & 416 & 711 \\
Faculdades Integradas & 203 & 162 & 180 & 208 & 10 & 1 & 7 & 11 & 193 & 161 & 173 & 197 \\
Faculdades, Escolas e Institutos & 423 & 426 & 676 & 1132 & 108 & 92 & 77 & 81 & 314 & 335 & 599 & 1051 \\
Centros de Educaçá̃o Tecnológica & $\ldots$ & $\ldots$ & 43 & 98 & $\ldots$ & $\ldots$ & 37 & 48 & $\ldots$ & $\ldots$ & 6 & 50 \\
\hline
\end{tabular}

Fonte: MEC/INEP. 
Nesse cenário, é oportuno situar que as Instituições Federais de Ensino Superior (IFES) no Brasil, a despeito da retração paulatina de recursos $^{10}$ e do seu quadro docente e técnico-administrativo, processo intensificado sobretudo no período entre 1995 e 2004, vivenciaram uma expansão de sua atuação. Tal expansão realizou-se, em grande parte, à custa da luta pela sobrevivência institucional no cenário sombrio da precarização de condições de trabalho e de infra-estrutura que, em muitos casos, redirecionou as ações de gestão e organização acadêmica das IFES, merecendo destaque a secundarização das atividades de pesquisa em várias instituições. Esse quadro começou a se alterar no que concerne ao repasse de recursos para manutenção das IFES ${ }^{11}$ e após a retomada da contratação de docentes e técnico-administrativos no Governo Lula, sobretudo no segundo mandato.

A discussão sobre a necessária expansão da educação superior no Brasil implica rediscutir as políticas e os marcos organizacionais e regulacionais vigentes e, sobretudo, a lógica privatista subjacentes às políticas de regulação e gestão desse nível de ensino. ${ }^{12}$ Esse movimento passa, necessariamente, por ações concretas, visando à ampliação das matrículas nas instituições públicas, cuja implicação básica remete a novos marcos na lógica de seu financiamento. A esse respeito, algumas ações vêm sendo desenvolvidas, destacando-se a criação de novas IES, incluindo universidades e institutos federais tecnológicos, bem como a expansão de vagas, a criação de novos cursos e a consolidação de campi nas universidades federais. ${ }^{13}$

Outra ação em curso, envolvendo as IFEs, é a expansão de cursos por meio da modalidade educação a distância, que se consubstancia em níveis articulados: a redefinição das ações da CAPES no campo da formação de professores, visando à busca de maior organicidade dos programas de formação inicial e continuada, e a consolidação da UAB.

A política de expansão da educação básica e superior: a formação de professores na modalidade a distância

Os indicadores e análises desenvolvidos, anteriormente, sinalizam para um complexo processo de expansão da educação básica e superior no Brasil e indicam enormes desafios à garantia do acesso e da qualidade da educação, em todos os níveis e modalidades. 
Políticas e gestão da educação superior a distância: novos marcos regulatórios?

Nesse processo expansionista, ganhou relevo a ênfase em políticas direcionadas à formação de professores, vistas, por muitos, como ações de grande importância para a melhoria da qualidade da educação brasileira. Muitas foram as políticas delineadas para o setor, nas duas últimas décadas, destacando-se a diversificação e diferenciação da educação superior (permitindo a criação de institutos superiores, por exemplo), a aprovação de diretrizes curriculares, novos programas direcionados à formação inicial e continuada, a criação da rede de formação, as mudanças nas políticas de financiamento, entre outras. Tais programas e políticas nem sempre se pautaram pela garantia de organicidade intrínseca, traduzindo-se, muitas vezes, por ações marcadas pela superposição e, em alguns casos, por dinâmicas contraditórias frente às concepçôes norteadoras, no marco de políticas emergenciais.

A partir da segunda metade da década de 1990, articulado ao processo expansionista da educação superior anteriormente apresentado, um novo ator passou a ocupar espaço de referência para as políticas de expansão e, particularmente, para a formação de professores: a ênfase na modalidade educação a distância. ${ }^{14}$

Assim, após a aprovação da Lei de Diretrizes e Bases da Educação Nacional (Lei n. 9394/96) e, sobretudo, após 2002, efetivou-se um processo de credenciamento de instituiçóes de educação superior para a oferta de cursos na modalidade a distância, com forte presenca da esfera privada. Os dados a seguir indicam o crescimento significativo do número de instituições credenciadas para a oferta de cursos de graduação, por meio da modalidade educação a distância. Segundo dados do INEP sobre a expansão da EaD, por nível administrativo, em 1999 tínhamos apenas duas IES credenciadas. Em 2007 esse número passou para 104 . O setor privado responde, nesse contexto, por 59,61\% das instituições credenciadas (62).

Em que pesem algumas ações direcionadas à efetivação de experiências no setor público, tal processo assumiu importância, sobretudo, na expansão em curso das IES privadas.

Se analisarmos os dados referentes às vagas oferecidas pelas IES para cursos na modalidade a distância por área e esfera administrativa, no censo da educação superior de 2006 (tabela 5) é clara a expressiva presença do ensino superior privado. Este setor responde por 96,12\% das 818.580 vagas oferecidas nessa modalidade de ensino, enquanto o 
ensino público responde por apenas 31.726 vagas oferecidas em 2006. Logo, é possível afirmar que há predominância de IES do setor privado, que têm buscado expandir significativamente o número de vagas por meio de cursos na modalidade EaD.

\section{Tabela 5}

Vagas oferecidas para cursos na modalidade a distância, por área e esfera administrativa - 2006

\begin{tabular}{|c|c|c|c|}
\hline & \\
\hline & & & Total \\
\hline \multirow[b]{2}{*}{ Educação } & Esfera pública & 18.912 & \multirow[b]{2}{*}{524.096} \\
\hline & Esfera privada & 505.184 & \\
\hline \multirow{2}{*}{$\begin{array}{l}\text { Ciências Sociais, } \\
\text { Negócios e Direito }\end{array}$} & Esfera pública & 12.294 & \multirow[b]{2}{*}{271.317} \\
\hline & Esfera privada & 259.023 & \\
\hline \multirow[b]{2}{*}{ Outras áreas } & Esfera pública & 520 & \multirow[b]{2}{*}{23.167} \\
\hline & Esfera privada & 22.647 & \\
\hline \multicolumn{3}{|l|}{ Total geral } & 818.580 \\
\hline
\end{tabular}

Fonte: MEC/INEP/DAES

Os dados revelam a prioridade às áreas de educação e de ciências humanas e sociais, responsáveis por 795.413 vagas na expansão por meio da EaD. A área de educação respondia, em 2006, por $64,02 \%$ das 818.580 vagas oferecidas e, nesse contexto, o ensino superior público respondia por apenas 18.912 delas. Tais indicadores nos permitem evidenciar como tendência que o processo de expansão de vagas em cursos na modalidade EaD vem ocorrendo com grande centralidade na área de educação e sob o controle da esfera privada.

No tocante ao número de matrículas efetivamente registradas no censo da educação superior, é significativa a participação da esfera privada, que, em 2006, respondeu por $81,52 \%$ das 207.991 matrículas registradas. $\mathrm{O}$ número de matrículas na esfera privada, em 2006, indica que ela vem oferecendo um número de vagas muito superior à demanda real (em 2006, o número de candidatos inscritos - demanda para a esfera privada - foi de apenas 373.297 de um total de 786.854 vagas disponibilizadas). 
Políticas e gestão da educação superior a distância: novos marcos regulatórios?

A área de educação, em 2006 (tabela 6), teve a maior ocorrência de matrículas, respondendo por $72,11 \%$ do total de matrículas efetivadas. A esfera pública respondeu por 37.205 das matrículas, ainda que paradoxalmente tenha oferecido apenas 18.912 vagas. Tais dados consubstanciam o efetivo predomínio de matrículas pelas IES da esfera privada, que, no caso da educação, foram responsáveis por 112.793 matrículas efetivadas.

\section{Tabela 6}

Matrícula por área e esfera administrativa - 2006

\begin{tabular}{|c|c|c|c|}
\hline & & & \\
\hline & & & Total \\
\hline & Esfera pública & 37.205 & \\
\hline Educação & Esfera privada & 112.793 & 149.998 \\
\hline Ciências Sociais, & Esfera pública & 830 & \\
\hline Negócios e Direito & Esfera privada & 54.064 & 54.894 \\
\hline & Esfera pública & 394 & \\
\hline Outras áreas & Esfera privada & 2.705 & 3.099 \\
\hline Total geral & & & 207.991 \\
\hline
\end{tabular}

Fonte: MEC/INEP/DAES

Dourado (no prelo) alerta, ainda, para limites no tocante à análise de dados relativos a matrículas na modalidade EaD. Nesse sentido, afirma que é

(...) importante destacar, ainda, que outros limites se interpõem à análise mais exaustiva dos dados sobre o real cenário da educação superior, por meio da modalidade EaD, uma vez que há instituições que, apesar de oferecerem cursos nesta modalidade, registram o número de matrículas nos cursos presenciais, o que requer levantamento e análise pormenorizados das informaçōes prestadas pelas IES e maior acompanhamento por parte do Ministério da Educação e, em particular, do INEP. Outro dado relevante refere-se à efetivação de disciplinas na modalidade EaD em cursos presenciais, com base na Portaria 2.253/2001, que permitiu a oferta de até $20 \%$ da carga horária de cursos presenciais na modalidade EaD. A 
aplicação da referida portaria não tem tido o devido acompanhamento pelo MEC, no tocante ao seu cumprimento por parte das IES. (p. 108)

As análises acusam a complexificação dos processos de expansão, com ênfase na área de educação, na modalidade EaD. Nesse cenário, o Ministério da Educação, de maneira mais orgânica nos dois últimos anos, vem buscando expandir as ações das instituições de educação superior públicas, em especial nas IFES, por meio da criação do sistema $\mathrm{UAB}$ e, mais recentemente, por meio de alterações político-administrativas significativas no tocante à formação de professores.

Para viabilizar tal processo, o MEC ampliou o espaço de atuação da Fundação Coordenação de Aperfeiçoamento de Pessoal de Nível Superior (CAPES), instituindo ações direcionadas à educação básica e à formação de professores. Ações estas que, anteriormente ao redimensionamento da CAPES, eram da competência das seguintes secretarias do Ministério: Secretaria de Educação Básica, Secretaria de Educação Superior e Secretaria de Educação a Distância.

Nesse processo de mudanças, ganha relevo, também, o papel do Insituto Nacional de Estudos Pedagógicos Anísio Teixeira (INEP) e do Fundo Nacional de Desenvolvimento da Educação (FNDE), que, respectivamente, consolidam a sua atuação como espaços de acompanhamento, avaliação e financiamento da educação nacional, sobretudo no tocante a projetos, programas e ações direcionados à educação básica e à formação de professores.

A UAB, segundo o MEC, tem por norte institucional a articulação entre as instituições formadoras (universidades federais e CEFETS) e os sistemas de ensino, através de parcerias financiadas pelo governo federal, objetivando a expansão da educação superior pública por meio de pólos em diferentes regióes e municípios brasileiros.

\section{A redefinição na política de formação de professores: a nova CAPES}

As políticas direcionadas à formação de professores vêm sendo objeto de vários estudos e pesquisa, bem como espaço de disputa de projetos que traduzem distintas concepções, nas últimas décadas. ${ }^{15}$

Nesse sentido, ganha relevância a análise da redefinição da política de formação de professores, historicamente dispersa em várias 
Políticas e gestão da educação superior a distância: novos marcos regulatórios?

políticas, programas e ações de diversas secretarias do MEC. Assim, o governo federal vem implementando ações em busca de maior organicidade entre os diversos setores que compóem a estrutura do Ministério e os que a ele se vinculam diretamente. Tendo o PDE como norte das atuais ações institucionais, o MEC sinaliza claramente para um redimensionamento de sua atuação, ao destacar a articulação entre a educação básica e a superior, por meio da prioridade a ações e políticas em várias áreas, destacando-se, entre elas, a formação de professores.

Nessa direção, o MEC complexificou e fortaleceu o papel da CAPES, ${ }^{16}$ ampliando suas ações na formulação de políticas públicas para a formação de professores da educação básica, por meio de projeto aprovado em junho de 2007. Não está claramente delineado o papel que será reservado às secretarias do $\mathrm{MEC}$, anteriormente responsáveis por ações no campo da formação de rofessores, especialmente as secretarias de Educação Básica, de Educação Superior e de Educação a Distância.

Redimensionada sua estrutura, a "nova" CAPES passou a contar com duas novas diretorias (Diretoria de Educação Presencial da Educação Básica e Diretoria de Ensino a Distância) e com um Conselho Técnico-Científico da Educação Básica. ${ }^{17}$ Essa "nova" CAPES, além de suas atribuiçôes anteriores, passou a coordenar a estruturação do Plano do Sistema Nacional de Formação, a busca da organicidade das políticas, programas e ações direcionadas à formação e à expansão da formação inicial e continuada, por meio, entre outras, da UAB.

Nesse cenário de mudanças, a EaD ganha foro privilegiado, na medida em que a UAB, criada em 2005, passa a ser espaço de atuação da recém-criada Diretoria de Educação a Distância. Problematizar tais indicadores se revela uma trama complexa, tendo em vista o cenário das próprias políticas para o setor, bem como os desafios no tocante à democratização do acesso à educação básica e superior, como indicamos anteriormente. Aliada a essa questão, a formação de professores, por meio da modalidade a distância, tem sido objeto de muitas polêmicas e disputas no que concerne a sua pertinência, qualidade, acompanhamento, produção de material didático-pedagógico, avaliação, centralidade ou não do papel do professor, entre outras questóes.

A análise dos indicadores relativos a essa modalidade, como apresentamos anteriormente, revela que a EaD se coloca como um espaço de efetiva expansão no cenário da educação superior brasileira, envolvendo IES públicas e privadas. 
Tais constatações nos remetem a questionar premissas históricas no campo educacional, tais como: a adesão acrítica à implementação da modalidade EaD, para muitos entendida como espaço de resolução dos problemas relativos à formação num país continental como o Brasil, bem como posições totalmente refratárias a EaD, por vislumbrar nessa modalidade a mera garantia de um processo de aligeiramento da formação inicial e continuada. Nesse contexto, é fundamental reconhecer que a centralidade conferida à forma de oferta de ensino negligencia o essencial, qual seja, o projeto pedagógico, as condições objetivas de ensino-aprendizagem, entre outros. Assim, é fundamental romper com a centralidade conferida ao aparato tecnológico e seu uso como os responsáveis diretos pela qualidade ou não do processo educativo.

Entendo que este embate é complexo e, certamente, não encontra resposta satisfatória nas duas posições que buscam hegemonia no campo. A esse respeito, é fundamental destacar que, segundo Dourado (2002, p. 237-238),

A ênfase ideológica dada a esses processos revela a mística de que estes resultam do advento tecnológico e não de opções econômicas e políticas que têm o mercado como portador de racionalidade e modelador das formas de organização social. $\mathrm{Na}$ contramão dessa compreensão é fundamental não perder de vista que as tecnologias não determinam a sociedade, "dado que a tecnologia é a sociedade, e a sociedade não pode ser representada sem suas ferramentas tecnológicas" (Castells, 1999, p. 25). Ou seja, as novas tecnologias não se apresentam como simples veículos da ideologia dominante ou ferramentas de entretenimento puro e inocente. Ao contrário, é fundamental compreendê-las como ferramentas produzidas e apropriadas socialmente, uma vez que as novas tecnologias incorporam e disseminam discursos sociais e políticos, cuja análise e interpretação não são uniformes ou padronizadas, o que exige métodos de análise e críticas capazes de articular sua inserção na economia política e nas relaçôes sociais em que são criadas, veiculadas e recebidas. Pensar o papel das novas tecnologias, nesse contexto, implica romper com a mística que acentua o papel das tecnologias da informação e comunicação (TIC) como as protagonistas sociais, remetendo ao necessário desvelamento do Estado em sentido amplo, entendido como espaço de luta política e expressão da condensação de forças entre sociedade civil e política, e de sua materialização no campo das políticas engendradas e materializadas pelo Estado na sociedade. Ou seja, é fundamental romper com a naturalização de concepções e sistemas políticos como se fossem meras decorrências de inflexốes de bases digitais ou resultantes da 
Políticas e gestão da educação superior a distância: novos marcos regulatórios?

pretensa hegemonia assumida pelos recursos midiáticos. Ao mesmo tempo, implica não perder de vista a complexidade do cenário sociopolítico em que as TIC assumem papel significativo, como veículo formativo, tendo em vista que imagens, sons, narrativas fornecem símbolos, mitos e recursos que favorecem a constituição do senso comum desagregado e funcional.

Problematizar tal cenário expansionista da educação superior e da formação de professores, em especial, nos remete a análises mais amplas das políticas para o setor, sem prejuízo de identificar os limites e possibilidades de processos de formação de qualidade, seja em cursos presenciais ou em cursos a distância.

\section{A "nova" CAPES, a UAB e a formação de professores por meio da EaD}

Segundo o MEC"18 "A UAB - Universidade Aberta do Brasil é um programa da Diretoria de Educação a Distância (DED) da Coordenação de Aperfeiçoamento de Pessoal do Ensino Superior (CAPES) com parceria da Secretaria de Educação a Distância (SEED) do Ministério da Educação (MEC)". Nessa direção, compete à UAB como "prioridade a formação e capacitação inicial e continuada de professores para a educação básica, com a utilização de metodologias da educação a distância”, envolvendo estados, municípios e "instituições de educação superior públicas para a oferta de cursos superiores a distância em pólos de apoio presencial, prioritariamente distribuídos em municípios do interior do país". Tais competências, em si, já deslindam opçôes teóricas e político-pedagógicas que merecem análise e debates envolvendo os diferentes atores no campo da formação.

Articulada a essas competências, a definição dos cinco eixos expressos, pelo MEC, como fundamentais para o sistema UAB, sinaliza, claramente, para o importante papel da UAB na expansão e consolidação de uma "nova" política de formação de professores no país. Os eixos mencionados são:

1) Expansão pública da educação superior, considerando os processos de democratização e acesso;

2) aperfeiçoamento dos processos de gestão das instituições de ensino superior, possibilitando sua expansão em consonância com as propostas educacionais dos estados e municípios; 
3) a avaliação da educação superior a distância tendo por base os processos de flexibilização e regulação em implementação pelo MEC;

4) as contribuições para a investigação em educação superior a distância no país;

5) o financiamento dos processos de implantação, execução e formação de recursos humanos em educação superior a distância.

Esses cinco eixos merecem análise pormenorizada, de modo a garantir a clara definição, por exemplo, do que se entende por: aperfeiçoamento dos processos de gestão das IES, avaliação tendo por base os processos de flexibilização e regulação (processos em curso, novos processos, flexibilização em relação a quê etc.), quais as bases para o financiamento, bem como as prioridades para a formação, quais as dinâmicas pedagógicas, entre outras, e, por conseguinte, as concepções norteadoras do processo de mudança e o novo estatus da relação Ministério da Educação e sistemas de ensino.

Nessa direção, destaca-se, de modo orgânico, a institucionalização da Diretoria de Educação a Distância (DED/CAPES) ${ }^{19}$ como locus privilegiado, cuja missão e papel objetivam a coordenação do Programa UAB, por meio de quatro coordenações: Coordenação Geral de Supervisão e Fomento (CGSF), Coordenação Geral de Articulação Acadêmica (CGAA), Coordenação Geral de Infra-estrutura de Pólos (CGIP) e Coordenação Geral de Políticas de Informação (CGPI), que revela a importância estratégica desta diretoria no novo desenho da CAPES.

Assim, segundo a CAPES, a consolidação da UAB, por meio da DED/ CAPES, objetiva dinamizar ações institucionais em curso, em busca de articulação das ações entre ${ }^{20}$ "instituições públicas de ensino superior, estados e municípios brasileiros, para promover, através da metodologia da educação a distância, acesso ao ensino superior para camadas da população que estão excluídas do processo educacional".

Se considerarmos as várias atribuições da DED, por meio de suas quatro coordenações, ${ }^{21}$ é possível identificar que as bases das políticas de formação de professores já se encontram em processo de efetivação. Tal constatação é corroborada pelos dados disseminados pela UAB. Em consulta ao site <http://uab.capes.gov.br/>, em agosto de 2008, foi possível identificar que já participam desse processo expansionista 49 
Políticas e gestão da educação superior a distância: novos marcos regulatórios?

IES, por meio das IFES e dos CEFETs, cuja cobertura em termos do número de pólos chega a 289 nos diferentes municípios brasileiros.

Sem menosprezar a importância de ações direcionadas à formação de professores (tanto presencial quanto por meio da modalidade a distância e, ainda, considerando que a busca de ações articuladas, de modo a romper com a fragmentação presente nas ações e programas de formação inicial e continuada, há muito tempo vem sendo reivindicada pelos setores acadêmicos e sindicais), proponho algumas questóes para a reflexão, neste momento de mudanças nas políticas de formação de professores: 1) por que a "nova estrutura" da CAPES dicotomizou a formação de professores em duas diretorias (uma presencial e outra a distância)?; 2) qual a concepção de formação que norteia as ações da "nova" CAPES?; 3) por que a CAPES e o MEC buscam a consolidação da UAB, num momento em que se discute no CTC de educação básica as bases para a estruturação do tão necessário sistema nacional de formação de professores?; 4) seria a modalidade "EaD”, por meio da UAB, um modelo de novas formas de articulação política e, portanto, um instrumento para se garantir a regulamentação do regime de colaboração entre os entes federados?; 5) qual o papel das secretarias de educação básica e superior nesse processo de mudança?; 6) qual o papel reservado à Secretaria de Educação a Distância nesse contexto?

São questões importantes a serem discutidas nesse momento de mudanças, o que, a meu ver, pode contribuir para a superação da histórica dicotomia entre educação presencial e a distância, por meio do equacionamento de bases nacionais comuns para a política de formação de professores, inicial e continuada, a fim de concretizar um sistema nacional de formação de professores, reivindicação histórica no campo educativo. Nessa direção, são extremamente oportunas as deliberações da Conferência Nacional de Educação Básica (CONEB), que destacam, em seu documento final:

1) no tocante à concepção de formação do profissional da educação, que “deverá se pautar pelo desenvolvimento de sólida formação teórica e interdisciplinar em educação de crianças, adolescentes, jovens e adultos, no campo e na cidade e nas áreas específicas de ensino, pela unidade entre teoria e prática, pela centralidade do trabalho como princípio educativo na formação profissional e pelo entendimento de que a pesquisa se constitui em princípio cognitivo e formativo e, portanto, eixo nucleador dessa formação. Deverá, ainda, considerar a vivência da gestão 
democrática, o compromisso social, político e ético com um projeto emancipador e transformador das relações sociais e a vivência do trabalho coletivo e interdisciplinar de forma problematizadora";

2) A formação dos/as trabalhadores/as em educação deve ser entendida na perspectiva social e alçada ao nível da política pública, tratada como direito, superando o estágio das iniciativas individuais para aperfeiçoamento próprio. Essa política deve ter como componentes, juntamente com a carreira, a jornada de trabalho e a remuneração, elementos indispensáveis à valorização profissional. Deve ser pensada como processo inicial e continuado, como direito dos profissionais da educação e dever do Estado;

3) A adoção das modalidades de formação, presencial ou por meio da EaD, deve ter por norte pedagógico a busca de uma formação de qualidade socialmente referenciada. Nessa direção, entende-se que o papel do professor é crucial para o bom andamento dos cursos, razão pela qual a dinâmica pedagógica deve enfatizar a ação docente em todos os momentos do processo formativo, optando pela manutenção do docente na implantação, acompanhamento, monitoramento e avaliação das ações de formação". (Brasil, 2008, p. 84 e 97)

Nessa direção, é fundamental não secundarizar a centralidade de se avançar na construção de políticas que se direcionem para a garantia da qualidade do ensino, o que, certamente, nos remete a pensar as políticas para a educação superior (envolvendo questóes anteriormente abordadas, como a centralidade conferida ao setor privado no tocante a oferta de matrículas, os processos de diversificação e diferenciação, os projetos pedagógicos dos cursos de formação inicial e continuada, entre outros) e uma maior articulação desse nível de ensino com as políticas para a educação básica, ganhando relevo, entre outras, a formação de professores e questóes relativas ao financiamento e gestão das diversas etapas e modalidades que compõem esse nível de ensino. Tais questões nos remetem à necessária efetivação de políticas de Estado, em detrimento de ações, programas e políticas setoriais nem sempre articulados.

\section{Considerações finais}

Ao longo do texto, sinalizamos indicadores que revelam a complexidade do sistema educacional brasileiro e, ao mesmo tempo, deslindam a necessidade de políticas articuladas que se direcionem para os diferentes níveis e modalidades educativas. A expansão com qualidade 
Políticas e gestão da educação superior a distância: novos marcos regulatórios?

da educação básica pressupõe, entre outras ações, uma política direcionada e orgânica para a formação de professores. Tal perspectiva analítica sinaliza para o redimensionamento de políticas, açōes e programas que contribuam para a garantia desta organicidade do campo da formação, envolvendo a formação inicial e continuada de professores.

Pensar políticas articuladas para a formação implica, portanto, romper com a dicotomia entre ensino presencial e ensino a distância que, no caso brasileiro, tem contribuído para posiçôes extremas de "fetichização" ora do ensino presencial, ora do ensino a distância. Isso pressupóe a necessidade de garantia de: projeto pedagógico que garanta uma sólida formação teórico-prática, professores com formação stricto sensu, condiçôes adequadas de oferta, de laboratórios e bibliotecas, material didático-pedagógico em cursos presenciais e a distância, ressaltando que estes últimos devem garantir, ainda e não somente, estrutura adequada de acompanhamento, por meio de encontros presenciais regulares, além de outros meios envolvendo as tecnologias de informação e comunicação.

Entendemos que o que se deve construir é um sistema nacional de formação de professores, preferencialmente de formação dos profissionais da educação, que, ao invés de fomentar a segmentação e superposiçôes das políticas para a formação inicial e continuada, contribua para o estabelecimento de parâmetros básicos nacionais a serem garantidos nas diferentes instituiçôes de ensino, nos diversos cursos e modalidades. Ou seja, a efetivação de um sistema nacional de formação dos profissionais da educação deve garantir uma base comum nacional para toda a formação, estabelecendo, assim, as exigências a serem contempladas na formação de professores e funcionários para a educação básica.

Tal processo implicaria a necessidade do aprimoramento dos processos de acompanhamento e de avaliação, de modo a contribuir com o desenvolvimento institucional e, consequentemente, com a melhoria dos processos de formação inicial e continuada de professores, hoje oferecidos em larga escala e, de maneira geral, com qualidade duvidosa em cursos presenciais e a distância, sobretudo em IES mercantis que respondem pela maioria das matrículas na área de formação de professores.

Outro aspecto de grande importância refere-se à regulamentação do regime de colaboração entre os entes federados, permitindo, desse modo, novas relaçóes, onde cada ente federado possa efetivamente 
partilhar da construção de um projeto nacional para a formação, avançando, assim, para a implementação de políticas de Estado na área de educação.

Sem negligenciar outras questões importantes, se impõe, ainda, a necessária expansão da educação superior pública em todas as áreas, ganhando centralidade a área de formação. Tal dinâmica expansionista implica o repensar das atuais políticas, no sentido de consolidar um conjunto de ações e de experiências bem sucedidas em andamento, mas supõe também a busca de ações que contribuam para a expansão, articuladas à melhoria das condições de oferta. Ou seja, é preciso expandir as matrículas e, ao mesmo tempo, otimizar a capacidade instalada, contratar novos professores, melhorar a infra-estrutura das instituições, entre outros.

Assim, a necessidade de otimizar a formação de professores impõe um repensar profundo das atuais políticas e dos múltiplos e complexos processos e espaços de sua regulação e regulamentação, ou seja, das múltiplas regulações vigentes. A expansão com qualidade da educação se articula a esse processo, na medida em que a formação inicial e continuada dos profissionais da educação se coloca como uma das dimensões de extrema importância na construção de um padrão de qualidade socialmente referenciada (entendido como espaço de inclusão e, ao mesmo tempo, de efetiva formação para todos, nos diferentes níveis e modalidades em que se estrutura a educação brasileira).

Essas ações certamente contribuirão para processos de maior articulação entre a educação básica e superior, contribuindo significativamente para a melhoria do processo de ensino-aprendizagem nestes níveis.

Nessa direção, a busca de maior articulação entre as secretarias do MEC (por exemplo, SEB, SEED, SESU) e a CAPES, bem como entre os diferentes programas, ações e políticas, se coloca como um ponto fundamental. Para tal processo se consolidar, faz-se necessário, ainda, o fortalecimento das ações do CTC de educação básica, bem como a articulação deste ao CTC de educação superior. No tocante às duas diretorias da CAPES, a ruptura com a atual dicotomia (presencial e a distância) deve ser superada de maneira a se pensar mais globalmente as políticas para a formação de professores.

Por fim, dadas as concepçôes de educação e de formação em disputa na arena educacional, tais políticas não têm se efetivado sem 
Políticas e gestão da educação superior a distância: novos marcos regulatórios?

recorrentes alterações. Desse modo, os espaços têm sido permeados por várias instâncias de regulação, envolvendo o Ministério da Educação, universidades e demais instituiçôes de ensino superior, sistemas de ensino, sindicatos, entidades acadêmicas, entre outros. Nesse cenário, a construção de um sistema nacional de formação, mediado pelo MEC, exigiria a abertura de diálogo entre os diferentes atores da área educacional. Tal constatação implica dizer que a proposição e a efetiva materialização de políticas de formação de profissionais da educação no Brasil só se consubstanciarão se devidamente discutidas como políticas de Estado e, portanto, como resultantes da articulação possível entre sociedade civil e política.

\section{Recebido e aprovado em setembro de 2008.}

\section{Notas}

1. A respeito do federalismo político e educacional no Brasil, Cury (2006, p. 113) faz um alerta de extrema importância: "O tratamento das políticas educacionais no Brasil e, muitas vezes, tomando sob a predominância da esfera federal. Com isso, pode-se deixar de tratar de modo procedente políticas educacionais que estão sob responsabilidade de Estados, municípios e Distrito Federal".

2. O Fundo de Manutenção e Desenvolvimento do Ensino Fundamental e de Valorização do Magistério (FUNDEF) foi implementado a partir de 1997 e, segundo Pinto (2007), a partir de sua implementação ficou mais evidente a participação dos municípios no atendimento educacional. A partir da evolução do número de matrículas no fundamental, segundo o autor (2007, p. 878), é possível constatar "que em todas as regiōes a municipalização avançou, de tal forma que a rede municipal, que em 1991 era responsável por 35\% das matrículas públicas do ensino fundamental (um patamar que remonta à década de 1950), passou a responder por $60 \%$ dessas matrículas em 2006)”.

3. Oliveira (2007), ao deslindar análises sobre a importância significativa da universalização do acesso ao ensino fundamental, destaca desafios no tocante à expansão de outras etapas da educação básica, destacando o ensino médio, ao mesmo tempo, que sinaliza para a articulação a esse processo da melhoria da qualidade neste nível da educação nacional.

4. A respeito da relação da educação profissional e tecnológica, a partir de uma concepção da “politécnica ou da tecnologia universal” com a educação básica, ver Frigotto (2007).

5. A esse respeito, Pinto (2007, p. 894) afirma que "muito embora o FUNDEB represente um avanço ante o FUNDEF, ao resgatar o conceito de educação básica e ao fortalecer o controle social, ele não enfrentou os dois principais problemas de nossa política de fundos: 1) a inexistência de um valor mínimo por aluno, que assegure um ensino de qualidade e que impeça as disparidades regionais; 2) embora o fundo seja único no ambito de cada unidade da Federação, os alunos permanecem atendidos por duas redes distintas, com padrôes de funcionamento e de qualidade distintos e que dificilmente conseguem estabelecer um regime de colaboração". 
6. Nessa direção, é oportuno situar as deliberações da Conferência Nacional de Educação Básica que, entre outros, destacam a importância do enfrentamento de cinco desafios para o Estado e para a sociedade brasileira: 1) promover a construção de um sistema nacional de educação que institua uma orientação política comum e de trabalho permanente do Estado e da sociedade, na garantia do direito à educação; 2) manter constante o debate nacional, estimulando e orientando a mobilização de diferentes segmentos sociais pela qualidade e valorização da educação básica, por meio da definição de referências e concepções fundamentais de um projeto de Estado abrangente, visando à consolidação de uma educação efetivamente democrática; 3) garantir que os acordos e consensos produzidos na Conferência Nacional de Educação redundem em políticas públicas, que se consolidarão em planos, programas, projetos e proposições pedagógicas e políticas, capazes de fazer avançar o panorama educacional da educação básica no Brasil; 4) propiciar condições para que as políticas educacionais, concebidas e implementadas de forma articulada entre os sistemas de ensino, promovam: o direito do aluno à formação integral com qualidade; o respeito à diversidade; a definição de parâmetros e diretrizes para a qualificação dos profissionais da educação; as condições salariais e profissionais imprescindíveis ao trabalho dos docentes e funcionários; a educação inclusiva; a gestão democrática e o desenvolvimento social; o regime de colaboração, de forma articulada, em todo o país; o financiamento e o controle social da educação; e a instituição de uma política nacional de avaliação; 5) indicar, para o conjunto das políticas educacionais implementadas de forma articulada entre os sistemas de ensino, que os seus fundamentos estão alicerçados na garantia da universalização e da qualidade social da educação básica, bem como da democratização da sua gestão (Brasil, 2008).

7. O PNE indica várias metas para a educação superior. Duas metas assumem importante papel no sentido de garantir a expansão de todo o sistema, resguardando a expansão pública: 1) prover, até o final da década, a oferta da educação superior para, pelo menos, $30 \%$ da faixa etária de 18 a 24 anos; 2) ampliar a oferta de ensino público, de modo a assegurar uma proporção nunca inferior a $40 \%$ do total de vagas, prevendo, inclusive, a parceria da União com os Estados na criação de novos estabelecimentos de educação superior (meta vetada). A respeito do PNE e de sua avaliação, ver Dourado (2006).

8. A respeito da diversificação e diferenciação na educação superior, ver Sguissardi e Silva Jr. (2001).

9. A respeito do processo de privatização de IES municipais públicas, ver Dourado (2001).

10. A esse respeito, conferir Amaral (2003), que desenvolve estudo substantivo sobre o financiamento das IFES, indicando uma lógica sempre decrescente dos recursos alocados pelo governo federal a estas instituiçóes, no período de 1998-2001.

11. O repasse de recursos para a manutenção das IFEs, no Governo Lula, segundo Amaral (no prelo), vivenciou incremento, sobretudo a partir de 2004.

12. A respeito desses processos no campo da educação superior, ver, entre outros, Catani e Giliolo (2005); Cunha (2007); Dias Sobrinho e Ristoff (2002); Dourado (2002) e Dourado, Catani e Oliveira (2003).

13. Destaca-se, nesse processo, a proposta de reforma universitária encaminhada pelo MEC e em tramitação no Congresso Nacional que sinaliza para: uma rediscussão da função social da educação superior, para alterações mais efetivas no tocante ao financiamento do ensino público, entre outros pontos. Por outro lado, assiste-se a uma reforma efetiva em curso, resultante do Plano de Desenvolvimento da Educação e da efetivação de outros dispositivos legais - decretos, portarias, resoluções -, com vistas a: garantir a criação de novas universidades federais, transformação de CEFETs em IFETs, criação de novos cursos, expansão por

Educ. Soc., Campinas, vol. 29, n. 104 - Especial, p. 891-917, out. 2008

Disponível em <http://www.cedes.unicamp.br> 
meio da modalidade educação a distância e, mais recentemente, pela edição do Programa de Apoio a Planos de Reestruturação e Expansão das Universidades Federais (REUNI), instituído pelo Decreto n. 6.096, de 24 de abril de 2007, bem como a busca de articulação entre gestão e avaliação, por meio da ênfase no Plano de Desenvolvimento Institucional e nos processos de avaliação - implementação do Sistema Nacional de Avaliação da Educação Superior (SINAES), entre outros. A respeito dos limites e possibilidades do PDE, ver Saviani (2007).

14. No texto, utiliza-se a expressão educação a distância, apesar de sua polissemia, ainda que o autor concorde com a diferenciação feita por Fetizon e Minto (2007) entre educação e ensino, ao afirmarem que "Há uma diferença clara entre educação e ensino. O conceito de educação é mais abrangente do que o do ensino (...) ensino não se confunde com educação, pois o primeiro é apenas um dos meios essenciais para se chegar à segunda".

15. A respeito desse movimento e de sua análise, no campo, vários artigos e documentos poderiam ser mencionados. Destaco, a seguir, a importância da atuação e produção de entidades do campo educacional como ANFOPE, ANPAE, ANPEd, CEDES, CNTE, FORUMDIR.

16. A esse respeito, ver Freitas (2007) e Dourado (no prelo).

17. São competências para CTC CAPES da Educação Básica no período 2008-2010: "Estabelecer prioridades e linhas gerais orientadoras das atividades da entidade, a partir de proposta apresentada pelo Presidente da CAPES; assistir à Diretoria-Executiva na elaboração das políticas e diretrizes específicas de atuação da CAPES no tocante à formação inicial e continuada de profissionais do magistério da educação básica e a construção de um sistema nacional de formação de professores; discutir diretrizes de longo prazo para a formação inicial e continuada dos profissionais do magistério da educação básica em serviço; fixar parâmetros para avaliação da demanda por profissionais do magistério da educação básica, inclusive para subsidiar a instalação de pólos municipais de apoio presencial; acompanhar a avaliação dos cursos de pedagogia, licenciatura e normal superior nos processos de avaliação conduzidos pelo INEP; manifestar-se nos processos de reconhecimento e de renovação de reconhecimento de cursos de pedagogia, licenciatura e normal superior, previamente à decisão da Secretaria competente; colaborar na elaboração de propostas, relativas à formação inicial e continuada de profissionais de magistério da educação básica, para subsidiar o Plano Nacional de Educação; opinar sobre a programação anual da CAPES, na área específica da educação básica; opinar sobre critérios e procedimentos para fomento a estudos e pesquisas relativos à orientação e conteúdo curriculares dos cursos de formação inicial e continuada de profissionais do magistério da educação básica; estabelecer parâmetros mediante os quais serão avaliados os programas de fomento e os cursos que receberem recursos financeiros da CAPES; propor a realização de estudos e programas para o aprimoramento das atividades da CAPES na sua área de atuação; opinar sobre assuntos que lhe sejam submetidos pelo Presidente da CAPES; e eleger seu representante no Conselho Superior" (disponível em: <www.mec.gov.br/sobre/ctceb.html>, acesso em: 01 abr. 2008).

18. Conferir site da CAPES "Organização administrativa" (disponível em: <http://uab.capes.gov.br>, acesso em: ago. 2008).

19. A presente análise, ao focalizar a Diretoria de Educação a Distância, não desconhece o papel atribuído à Diretoria da Educação Básica Presencial (DEB), que vem desenvolvendo, entre outras açôes, estudos e tem sob sua responsabilidade o Programa de Consolidação das Licenciaturas Prodocência, que tem por objeto "selecionar propostas que contemplem um conjunto de atividades relevantes para a formação e para o exercício profissional dos futuros docentes e que fortaleçam a formação do professor, tendo o trabalho pedagógico como princípio articulador da unidade entre teoria e prática na formação e atuação do educador. 
Em particular, apóia iniciativas que priorizam o acompanhamento e avaliação dos projetos político-pedagógicos dos diferentes cursos de licenciatura, bem como o desenvolvimento e a consolidação de novas metodologias articuladas aos conteúdos curriculares, com destaque para atividades apoiadas nas Tecnologias de Informação e Comunicação - TIC", bem como, ainda, o Programa de Bolsa Institucional de Iniciação à Docência (PIBID), com vistas a "contribuir para o aumento das médias das escolas participantes do Exame Nacional do Ensino Médio (ENEM)” (disponível em: <www.capes.gov.br/educacao-basica/prodocencia.htmail> e <www.capes.gov.br/educacao-basica/pibid.htmail>, acesso em: agosto de 2008).

20. Disponível em: <http://uab.capes.gov.br>, acesso em: ago. 2008.

21. Compete as essas coordenações: 1) a CGSF: "Definir parâmetros de financiamento, gerenciar a execução dos recursos financeiros, aprovar, acompanhar e fiscalizar os projetos que promovam a implantação e implementação da educação a distância nas instituições públicas de ensino superior, atender as demandas do Sistema Geral de Bolsas - SGB, cadastrando e autorizando o pagamento de bolsistas no âmbito do Sistema Universidade Aberta do Brasil UAB, orientar os coordenadores da UAB em suas necessidades referentes à Coordenação"; 2) a CGAA: "Supervisionar e acompanhar, em cooperação com as IES, a montagem e manutenção da infra-estrutura dos núcleos de gestão acadêmica e operacional dos cursos da UAB. Articular as Instituições Públicas de Ensino Superior e os pólos de apoio presencial, na definição dos cursos ofertados. Acompanhar o desempenho dos cursos oferecidos nos pólos de apoio presencial"; 3) a CGIP: "Supervisionar e acompanhar a infra-estrutura dos pólos, através de relatórios emitidos periodicamente pela coordenaçôes dos pólos. Acompanhar o desenvolvimento dos cursos nos pólos de apoio presencial" e 4) CGPI: "Promover e articular a indução e a avaliação de políticas para a criação de sistemas de tecnologias da informação das Instituiçōes de Ensino Superior no âmbito do Sistema UAB. Estabelecer diretrizes, normas e recomendações como instrumentos voltados ao apoio de processos de gestão da UAB, bem como gestão acadêmica e operacional relativas às IES e aos pólos de apoio presencial vinculados ao Sistema UAB" (disponível em: <http://uab.capes.gov.br>, acesso em: ago. 2008).

\section{Referências}

AMARAL, N.C. Financiamento da educação superior: Estado x mercado. São Paulo: Cortez, 2003.

AMARAL, N.C. Autonomia-avaliação-financiamento: em FHC e Lula. In: Dourado, L.F (Org.). Políticas e gestão da educação no Brasil: novos marcos regulatórios. São Paulo: Xamã. (no prelo).

BRASIL. Ministério da Educação. Diretrizes gerais do Programa de Apoio a Planos de Reestruturação e Expansão das Universidades Federais - REUNI. Disponível em: <http://portal.mec.gov.br/sesu/arquivos/ pdf/ diretrizesreuni.pdf>. Acesso em: ago 2008.

BRASIL. Ministerio da Educação. Documento final da Conferência $\mathrm{Na}$ cional de Educação Básica. Disponível em: <http://portal.mec.gov.br/arquivos/conferencia/documentos/doc_final.pdf>. Acesso em: ago. 2008.

Educ. Soc., Campinas, vol. 29, n. 104 - Especial, p. 891-917, out. 2008

Disponível em <http://www.cedes.unicamp.br> 
Políticas e gestão da educação superior a distância: novos marcos regulatórios?

BRASIL. Ministério da Educação. O Plano de Desenvolvimento da Educação: razões, princípios e programas. Disponível em: <http:// portal.mec.gov.br/arquivos/pdf/livromiolo v4.pdf>. Acesso em: jul. 2008.

CATANI, A.M.; GILIOLO, R.S.P. O PROUNI na encruzilhada: entre a cidadania e a privatização. Linhas Críticas, Brasília, DF, v. 11, n. 20, p. 55-68, jan./jun. 2005.

COORDENAÇÃO DE APERFEIÇOAMENTO DE PESSOAL DE NIVEL SUPERIOR (CAPES). Universidade Aberta do Brasil. Disponível em: <http://www.uab.capes.gov.br/>. Acesso em: ago. 2008.

CUNHA, L.A. O desenvolvimento meandroso da educação brasileira entre o Estado e o mercado. Educação \& Sociedade, Campinas, v. 28, n. 100, p. 809-829, out. 2007.

CURY, C.R.J. Federalismo político e educacional. In: Ferreira, N.S.C. (Org.). Políticas públicas e gestão da educação: polêmicas, fundamentos e análises. Brasília, DF: Liber Livro, 2006. p. 113-129.

DIAS SOBRINHO, J.; RISTOFF, D.I. (Org.). Avaliação democrática para uma universidade cidadã. Florianópolis: Insular, 2002. p. 99-118.

DOURADO, L.F. A formação inicial e continuada de professores e a educação a distância no Brasil: um caminho para a expansão da educação superior? In: Lisita, V.M.S.; PeiXoto, A.J. (Org.). Formação de professores, políticas, concepçôes e perspectivas. Goiânia: Alternativa, 2001. v. 1, p. 69-80.

DOURADO, L.F. A interiorização do ensino superior e a privatização do público. Goiânia: UFG, 2001.

DOURADO, L.F. Reforma do Estado e as políticas para a educação superior nos anos 90. Educação \& Sociedade, Campinas, v. 23, n. 80, p. 235-253, set. 2002 .

DOURADO, L.F. Plano Nacional de Educação: avaliações e retomada do protagonismo da sociedade civil organizada na luta pela educação. In: Ferreira, N.S.C. (Org.). Políticas públicas e gestão da educação: polêmicas, fundamentos e análises. Brasília, DF: Liber Livro, 2006. p. 21-50. 
DOURADO, L.F. Políticas de expansão da educação superior no Brasil e a modalidade EAd. In: Mancebo, D.; Silva Junior, J.R.; OliveIra, J.F (Org.). Reformas e políticas: educação superior e pós-graduação no Brasil. Campinas: Atomo \& Alínea. (no prelo).

DOURADO, L.F; CATANI, A.M.; OLIVEIRA, J.F. (Org.). Políticas e gestão da educação superior: transformações recentes e debates atuais. São Paulo: Xamã; Goiânia: Alternativa, 2003.

FETIZON, B.A.M.; MINTO, C.A. Ensino a distância: equívocos, legislação e defesa da formação presencial. Universidade \& Sociedade, Brasília, DF, v. 39, p. 93-105, 2007.

FREITAS, H.C.L. A (nova) política de formação de professores: a prioridade postergarda. Educação \& Sociedade, Campinas, v. 28, n. 100, p. 1203-1230, out. 2007.

FRIGOTTO, G. A relação da educação profissional e tecnológica com a universalização da educação básica. Educação \& Sociedade, v. 28, n. 100, p. 1129-1152, out. 2007.

IANNI, O. Enigmas da modernidade-mundo. Rio de Janeiro: Civilização Brasileira, 2000.

OLIVEIRA, R.P. Da universalização do ensino fundamental ao desafio da qualidade: uma análise histórica. Educação \& Sociedade, Campinas, v. 28, n. 100, p. 661-690, out. 2007.

PINTO, J.M.R. A política recente de fundos para o financiamento da educação e seus efeitos no pacto federativo. Educação \& Sociedade, v. 28, n. 100 , p. $877-897$, out. 2007.

SAVIANI, D. O Plano de Desenvolvimento da Educação: análise do projeto do MEC. Educação \& Sociedade, Campinas, v. 28, n. 100, p. 1231-1255, out. 2007.

SGUISSARDI, V.; SILVA Jr., J.R. Novas faces da educação superior no Brasil: reforma do Estado e mudança na produção. 2. ed. São Paulo: Cortez; Bragança Paulista: UsF, 2001. 